\title{
Concept of development of geo-information complex of electrical distribution networks of railway junction
}

\author{
Alexey Kashtanov ${ }^{1, *}$, Elena Sidorova ${ }^{1}$, and Nadezda Ananieva ${ }^{1}$ \\ ${ }^{1}$ Omsk State Transport University, 644046, Marx av., 35, Omsk, Russia
}

\begin{abstract}
The paper considers one of the directions for the innovative development of a non-traction power supply system for railway transport by developing an electronic application that provides for the construction of a geo-information model of the complex of electrical distribution networks of a railway junction. The description of the basic principles of construction of the model of electrical distribution networks, the architecture of the developed complex and its functional capabilities is given.
\end{abstract}

\section{Introduction}

Nowadays, one of the most promising areas for the development of the energy complex in Russia as a whole and in its individual sectors is the development and subsequent implementation of digital technologies, including the creation of digital substations and digital electrical distribution networks. Digitalization is aimed at solving such problems as increasing the efficiency of interaction between various entities of the energy market (first of all, suppliers and consumers of energy resources), implementing remote connection and disconnection of electrical power, increasing the efficiency of the energy system through operational control of the operating modes of electric grid equipment, automatic detection and elimination of technological violations and emergency modes.

The railway transport is not an exception. At the same time, it should be noted that JSC "Russian Railways", which owns distribution electrical networks, has its own specifics that distinguishes it from other participants in the electricity market. Specificity is that the electric power complex of "RZD" is divided by types of activity for services on the use of the public railway transport infrastructure and services for the transmission of electrical energy to third-party consumers, which in turn leads to inconsistency with the requirements of the current legislation regarding the separate recording of costs for electrical network activities and technological connection of consumers to electrical networks. This specificity should be taken into account when developing any automated and IT systems for distribution networks of railway transport.

\footnotetext{
*Corresponding author: kesh-al@rambler.ru
} 


\section{Object of research}

Electrical distribution networks (hereinafter - EN) of railway junctions are characterized by a combination of different voltage classes from 0.4 to $10 \mathrm{kV}$. The analysis of the operating mode of EN requires a complex consideration of both its separate technological element and their interactions. Analysis of the current situation about EN of the JSC "RZD" [1] confirms the conclusion about the lack of available information for its comprehensive monitoring. The data on electrical equipment are usually not systematized, and for performance of an assessment of efficiency and reliability of work of EN, it is necessary to consider them in topological connection with other elements of EN.

One of the possible technical solutions on this issue may be the development of a geoinformation complex of electrical distribution networks of the railway junction (hereinafter referred to as GES GU). The basis for the development of this complex is the standard IEC 61970-301 "General information model" used in the world practice that establishes a semantic description and topology of electric grid objects in the form of a conceptual data model [2]. Functionally, GES GU should provide for the possibility of analyzing and systematizing data on the structure of $\mathrm{EN}$, technical parameters of objects, consumers of electricity in conjunction with geo-information about their location.

The proposed complex is an alternative to the existing SCADA systems, which does not require the modernization of the distribution network of the railway junction, i.e. introduction of expensive intelligent measuring and switching devices.

The availability of technical ability to build a network junction model using the tools contained in the electronic application of the geo-information complex will allow using it throughout the whole railway network without the need for additional material costs.

\section{Results}

Geo-information complex GES GU includes a GPS marker consisting of a receiver that receives a signal from the satellite and a module that transmits it to the server with an electronic application installed on it (Figure 1).

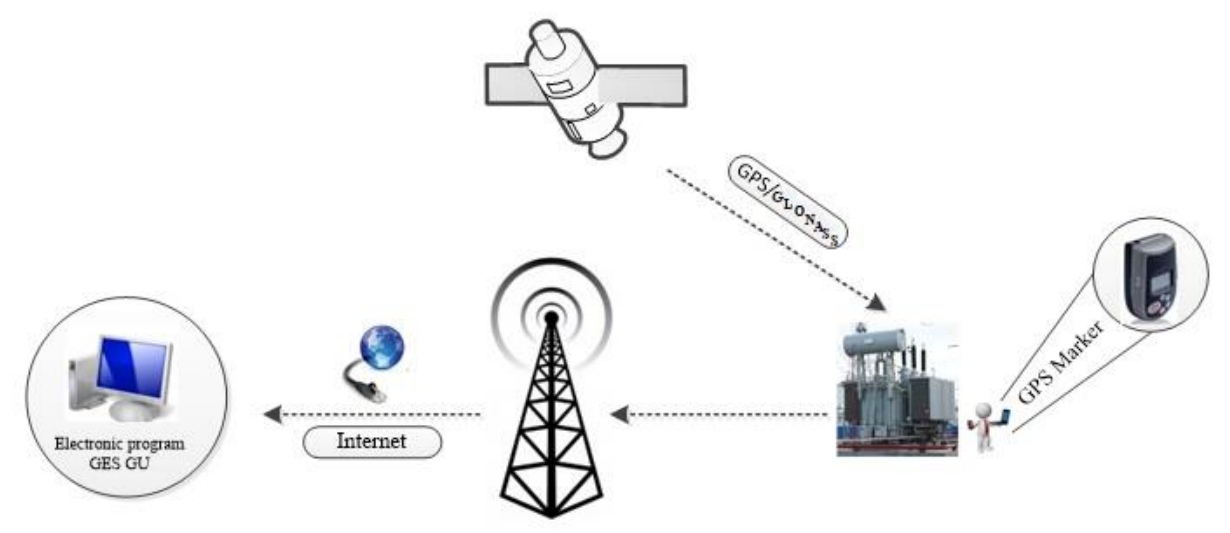

Fig. 1. Simplified structure of GES GU.

When activated, the GPS-Marker receives a signal from the satellite, determines the coordinates, and sends them to the server. In this case, the type of the object (district or transformer substation, power transmission line support, etc.) is indicated. Based on the received coordinates, a map-scheme of distribution networks is developed with the subsequent introduction of the initial information on electric grid objects. 
The architecture of the geo-information complex is a functionally distributed structure consisting of a set of interrelated elements, each of which is an independent component. The GES GU complex provides for the construction of a model of an electrical network using the symbols of a conditional graphic designation of objects: distribution and transformer substations, power transmission lines, disconnecting devices, switches and the displaying of operational information about their operation modes.

Due to the multi-level nature of EN, it is advisable to represent the information structure of the model by layers (many information layers $M L$ ) [3]:

$$
M L=\bigcup_{j=1}^{k} m_{j}
$$

where $m l_{j}$ - information layer of EN.

In this setting, the information structure of the complex is divided into clusters, each of which has a single level of information provided and certain operational effects.

Because of the multi-level structure of GES GU, the basic principles of building a system for storing and displaying information are realized, namely:

1) flexibility - the ability to present information in various forms in accordance with the required specification;

2) versatility - the ability to store an arbitrary set of characteristics of any object of EN;

3) compactness - access to the original information without duplicating it at each level.

In general, it is advisable to develop the cluster structure of GES GU in full accordance with the three-level structure of the metering system for power consumption at railway junctions [4]:

1) the level of reception (arrival) of electric power in the network of the railway junction;

2) the level of electric power distribution to transformer substations;

3) the level of supply (distribution) of electric power from the networks of the railway junction to the railway and third-party consumers of JSC "RZD".

The data necessary for the operation of GES GU can also be divided in terms of the degree of constancy into three groups: reference information, semi-constant and variable data. The group of reference (constant) information includes tabular (producers' catalogs, technical reference books), normative-technical, and graphic data. Semi-constant data includes the characteristics of the technological equipment of EN, the schemes of power supply and sectioning of transformer substations, the list and characteristics of electric power consumers, etc. Variable information is used as input data on the basis of reference and semi-constant information for solving the required problems. All constant and semiconstant information (names of objects, schemes, constant design parameters, etc.) should be unchanged during the design-basis time interval. At the same time, the reliability of the information complex largely depends on the reliability of this information.

As it was mentioned above, one of the purposes of the geo-information complex is the binding of data on network objects to the location map. To do this, it is necessary to implement a configuration that provides loading of geo-data on the working window of the electronic application from ready-made vector maps of the service area of the power supply network regions. This function is implemented, as a rule, through available Internet georesources, such as the Internet service YandexMaps (Figure 2) or GoogleMap (Figure 3). 


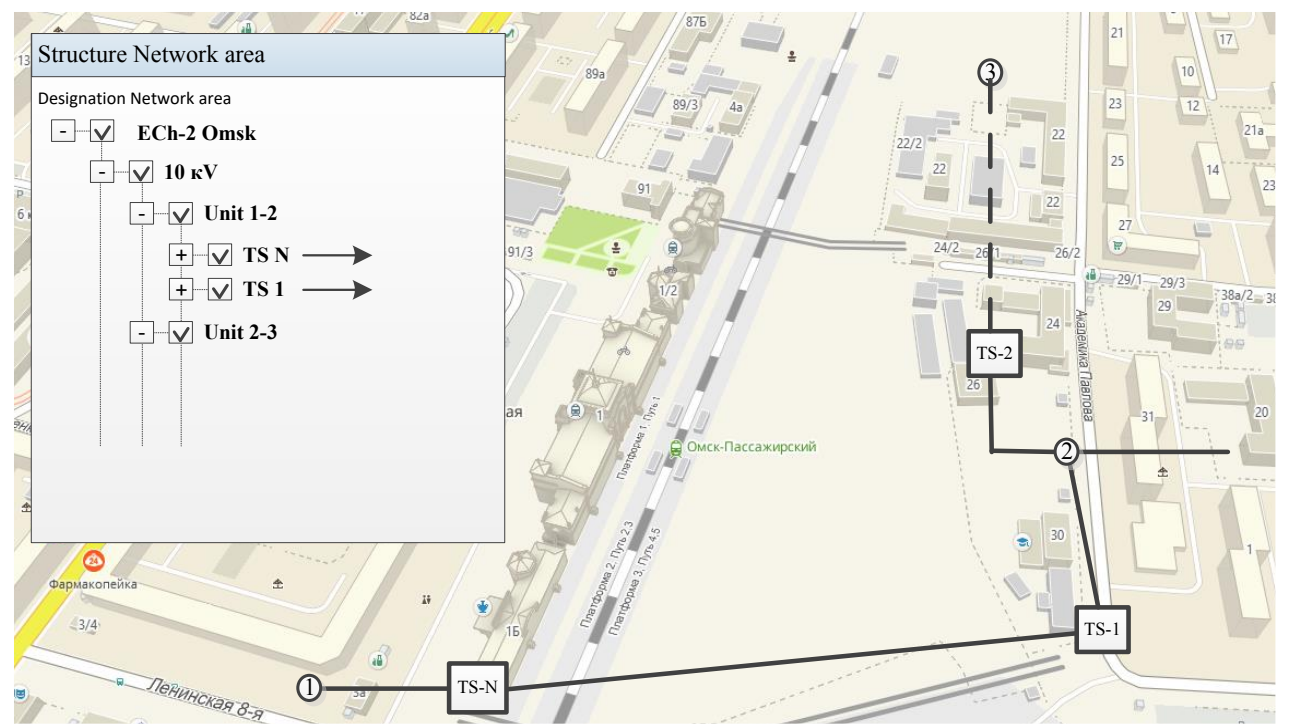

Fig. 2. The image of electric power network objects on a substrate Yandex Maps.

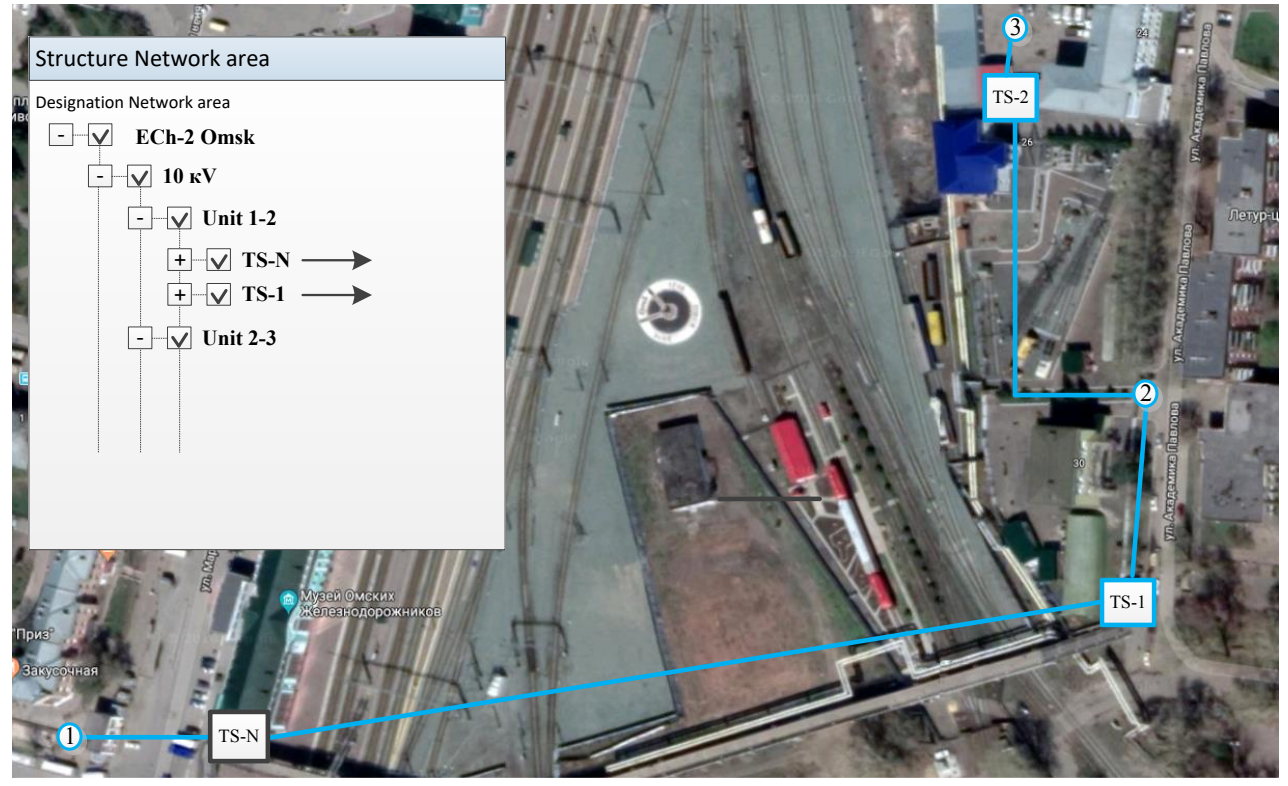

Fig. 3. The image of electric power network objects on a substrate GoogleMap.

When creating a model of the electric power network junction, the objects on the map are placed on the information layers corresponding to the structure of GES GU. The choice of displayed layers is arbitrary, depends on the required level of specification of the railway junction scheme, and is able to vary depending on the task. For example, when calculating the free power of transformer substations, a subsystem limited only by the substation will be considered. If the problem of calculating the balance of reception and distribution of electric power at the railway junction as a whole is considered, then it is not necessary to examine in detail the internal structure of each transformer substation separately.

The architecture of GES GU is built on the basis of the object-oriented principle of building a model of EN. Each object can be assigned an individual characteristic, for 
example, such as a parameter or property that describes its purpose or mode of operation. The main objects of the EN model are: power sources (district (RP) or traction (EChE) substations), transformers, supports, air or cable power transmission lines, switching devices, tires, consumers, etc.

The organization of the structure of EN of the railway junction is shown in Fig. 4.
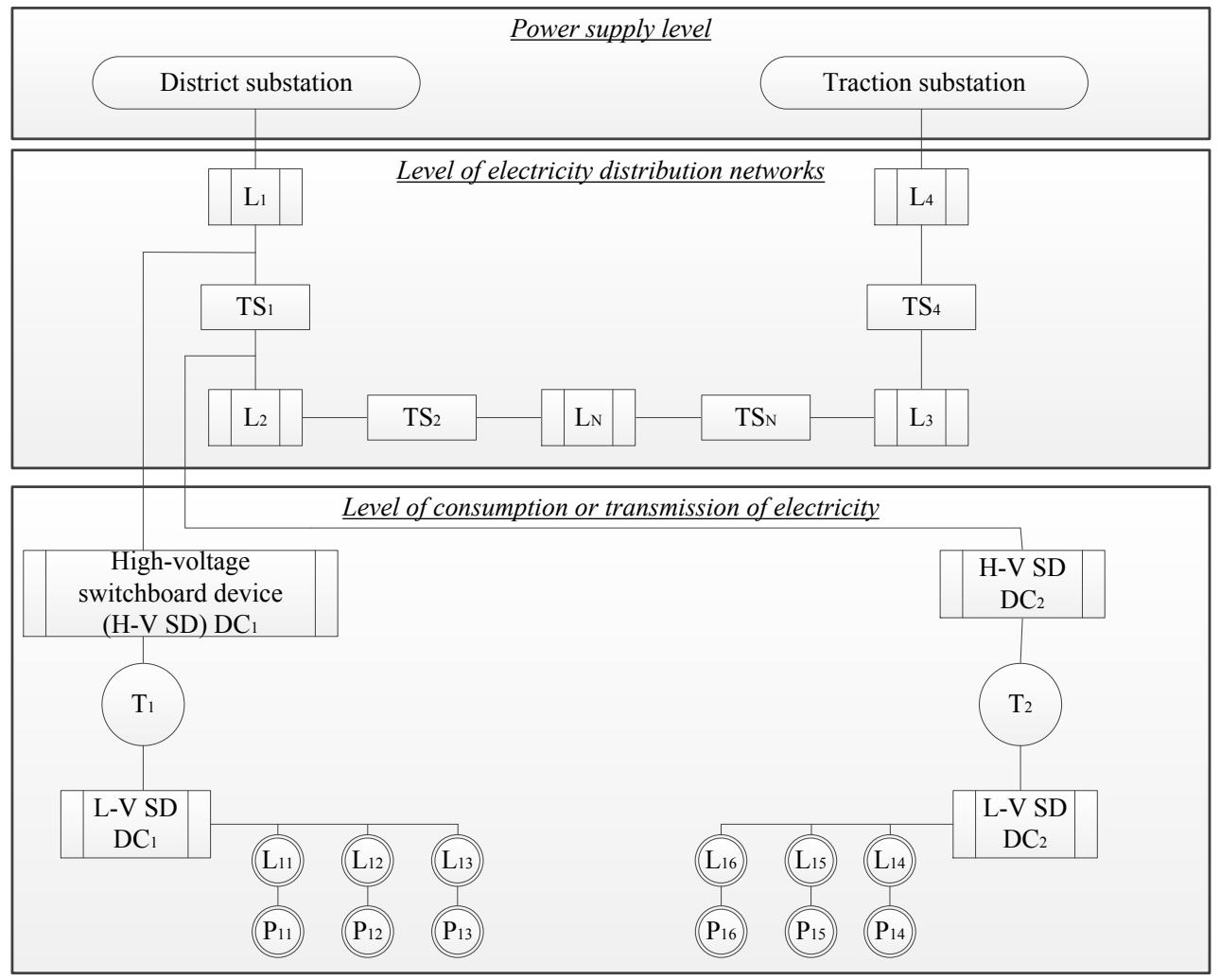

Fig. 4. Structure of the distribution networks of the railway junction.

As already noted, the topological model of the electric power distribution network is built on the principles set out in the standard IEC 61970-301. When building the model, the unified modeling language (UML) $[5,6]$ is used. Information on the topology of EN is formed in such a way that each node of an elementary object is "connected", i.e. it refers to an object of another level or information layer. With this approach, each elementary object (transformer, power transmission line, consumer, etc.) has a connection with a certain level (power supply area, substation, switchgear). An example of building connections of the topological model of electric power grid facilities is shown in Fig. 5. 


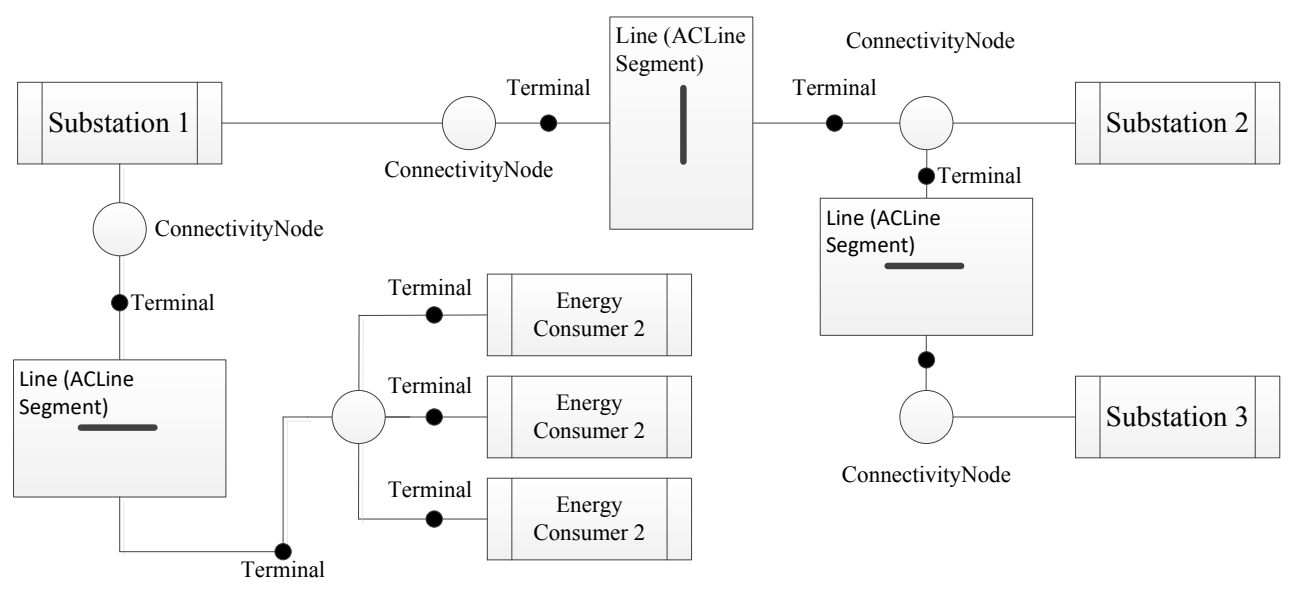

Fig. 5. Topological model of connectivity of power grid facilities.

The main conditions for building digital distribution networks are:

- integration into the network of intelligent switching devices for the purpose of automatic identification and localization of damages in distribution networks;

- modernization of existing power centers in the part of replacing outdated switching devices and PSP devices with modern vacuum circuit breakers and digital controllers of connections using digital combined current and voltage sensors;

- creation of a SCADA-system of the level of the area of electrical networks with $100 \%$ integration into the control network of automatic switching devices and the display of all non-automatic switching devices.

The existing equipment of the power grid complex of JSC "RZD" does not meet the requirements for "digital networks". Thus, the information space of GES GU complex, unlike the system SCADA systems built on the basis of the common information model (CIM), has an a posteriori interaction scheme, i.e. without taking into account inter-system interaction with other information and measuring complexes of the railway junction. This choice is determined both by much lower financial costs and by the availability of the possibility of introducing such a complex in various network areas without the need to upgrade existing electrical equipment. Further development of GES GU is possible through the construction of a priori interaction schemes, for example, when creating a unified scheme of interaction with automated systems for commercial metering of electricity at the railway junctions and the retail market [7].

\section{Conclusions}

Improvement of electric power consumption management systems and increase of reliability of electric power supply can be achieved through the development of automated workplaces that perform the functions of monitoring and analysis of the electricity metering system, as well as the automation of calculations of the operating modes of electric grid facilities.

The developed geo-information complex is designed to create, store, convert large volumes of geo-data, to represent geo-information and manage the spatially distributed resources of the power grid complex within the boundaries of railway junctions.

Creation of GES GU will allow: 
- creating models of electrical networks using symbols of conditional graphic designation of power grid facilities: distribution and transformer substations, power transmission lines, disconnecting devices, switches, etc.;

- ensuring the display of operational information on the operating modes of distribution networks;

- forming databases on equipment and subscribers with reference to transformer substations;

- providing automation of calculations of operating modes of electric grid facilities, including: calculation of free capacity of transformer substations, calculation of technical losses of electric energy;

- ensuring the formation of a balance sheet for the reception and distribution of electrical energy within the boundaries of the railway junction to identify feeders with high energy losses and to organize operational coordination with retail companies and consumers.

The social effect is achieved by increasing the reliability of electric power supply to all categories of consumers, by the safety of performing operational and repair work at power grid facilities, and by getting a tool at the disposal of workers of power supply divisions and Transenergo for analyzing the efficiency of the operating modes of electrical distribution networks.

\section{References}

1. A.L. Kashtanov, N.G. Ananyeva, Izvestiya Transsiba 1(33), 79 - 87 (2018)

2. IEC 61970: Energy Management System Application Program Interface (EMS-API)Part 301: Common Information Model (CIM) Base, Third Edition

3. S.E. Kokin, Energy information models of functioning and development of power supply systems of large cities: Thesis for a scientific degree of the doctor of technical sciences (Ekaterinburg, 2013)

4. A.L. Kashtanov, M.M. Nikiforov, I.Yu. Norkin, Increasing the efficiency of monitoring electric power consumption for traction of trains and non-traction needs according to ASKUE, Monograph (Omsk State Transport University, Omsk, 2010)

5. W. Boggs, M. Boggs, UML and Rational Rose (SYBEX, 2004)

6. M.I. Londer, A.I. Mikhailov, Energy of a unified network 2(13), 46 - 51 (2014)

7. A.L. Kashtanov, A.A. Komyakov, I.Yu. Norkin, Izvestiya Transsiba 2(2), 71-76 (2010) 